\title{
Insect heart resonance appearance simulation of Colorado potato beetle (leptinotarsa, doryphora, decemlineata say)
}

\begin{abstract}
Aims: The aim of this work was to simulate a multi-chamber system of insect heart, to determine the rigidity of its multi-chamber system and the resonant frequency.

Results: Currently, it is important to solve the problem of the destruction of plant pests, namely the Colorado beetles. A method was developed for mechanical system resonant frequencies determining, which thereby make a scheme for a complex multi-chamber system of insect heart of Colorado potato beetle based on the electro-acoustic analogies method. The resonance properties simulation of insect heart was conducted by electromechanical analogies approach. Resonant frequency of the multi-chamber acoustic system of the Colorado potato beetles was calculated. Estimated that it is $1179[\mathrm{~Hz}]$
\end{abstract}

Volume 4 Issue 3 - 2019

\author{
Galyna I Sokol, Tatyana L Savchuk, Denis V \\ Larichev, TA Ribalka, ES Mironenko \\ Oles Honchar Dnipro National University, Ukraine
}

Correspondence: Galyna I Sokol, Oles Honchar Dnipro

National University, Ukraine, Email gsokol@ukr.net

Received: April 23, 2019 | Published: May 27, 2019

Keywords: body mechanical properties, insect heart, resonant frequency, hardness

\section{Introduction}

Insect's class is the most numerous, comprising more than 1 million species. Insects have inhabited a variety of terrestrial habitats, soil, fresh water, coastal seas. A large variety of habitats in the terrestrial environment contributed to the speciation and the wide distribution of this large group of arthropods. Most insects benefit as plants pollinators, some of them produce substances (honey, wax, varnish, silk), which are used as food products and raw materials for industry. Through the large biomass and diversity of trophic relations, insects take part in the biosphere circulation of substances, in soil formation processes. Among the insects that do not benefit, there are pests of forest and agricultural crops, carriers of plant, animal and human diseases. For example, potato or Colorado potato beetle (Leptinotarsa, Doryphora, decemlineata Say). It belongs to the tongs family (Crysomelidae), up to $1 \mathrm{sm}$ in length and up to $7 \mathrm{~mm}$ in width. Their body is reddish-yellow, elytra light yellow with 5 black longitudinal stripes; there are several black dots on their chest shield, sometimes merging into spots; the apex of thickening antennae and the posterior margin of the head are also black. The potato beetle was discovered and described in 1823 in the Rocky Mountains, where it inhabited and ate at the expense of wild-growing members of the nightshade family (Solaneae); later it switched to the colonists potato plantations. The first devastations produced by it were noticed in 1859 in the state of Colorado - hence the name of the beetle. ${ }^{1-6}$ The Colorado potato beetle causes great damage to the potato crop. Destruction is an important issue. The Colorado potato beetle has a multi-chamber heart. We believe that this is the most vulnerable part of his body. The heartbreak leads to the death of the Colorado potato beetle. This determines the relevance of the chosen topic. The aim of this work was to simulate a multi-chamber system of insect heart, to determine the rigidity of its multi-chamber system and the resonant frequency.

\section{Main part}

The heart of the insect has the following form. It is shown in Figure $1 .{ }^{7}$

\section{Physical model of insect heart}

For Colorado potato beetle heart resonant frequency determining, is necessary to calculate heart mass and its rigidity like a multi-chamber system. For such systems analyzing, it is reasonable to develop a unified theory based on the Lagrangian formalism, in which three systems-mechanical, electrical, and acoustic-are treated in the same way. This method names "electroacoustic analogies". The system of electroacoustic analogies contain following correspondences: pressure-electrical voltage, volumetric velocity-electrical current, electrical resistance-acoustic resistance, electrical capacitance-total compressibility of the volume, inductance-mass.

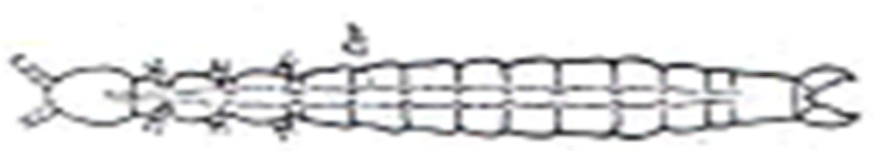

Figure I The heart of the insect.

Therefore, in work based on electroacoustic analogies methodology was developed a methodology for determining mechanical system resonant frequencies which replaces insect heart. Multi-chamber acoustic system scheme is shown in Figure 2. It based on the data from source. ${ }^{2}$ Because insect heart is not a continuous thin rod, but interconnected chambers filled with blood; let us represent the heart system as a form of successively connected chambers resembling a kind of filter. There are some holes, spines in the connections of the individual chambers.

\section{Mathematical model}

Studying design scheme of the oscillating system is depicted as discrete masses interconnected by elastic connections. When solving the problem of calculating the frequency characteristics of an oscillating system, it is replaced by an equivalent one. It is necessary to determine mechanical system mass and stiffness which is analogous to the insect heart. Based on these quantities knowledge's, heart resonant frequency is determined.

Body or a separate organ resonant frequency of a live insect from the expression (3) 


$$
f=\frac{1}{\partial} \sqrt{\frac{C}{m}},
$$

where C - system stiffness; $\mathrm{f}$ - resonant frequency; $\mathrm{m}$ - body tissue mass.

It is known that the reduced stiffness of an equivalent mechanical system with a series connection of elements is equal to [2].

$$
\frac{1}{C_{1}}+\frac{1}{C_{2}}+\ldots \ldots+\frac{1}{C_{n}}
$$

Where $\mathrm{C}_{1}, \mathrm{C}_{2}, \ldots \ldots, \mathrm{C}_{\mathrm{n}}$ - stiffness in some areas.

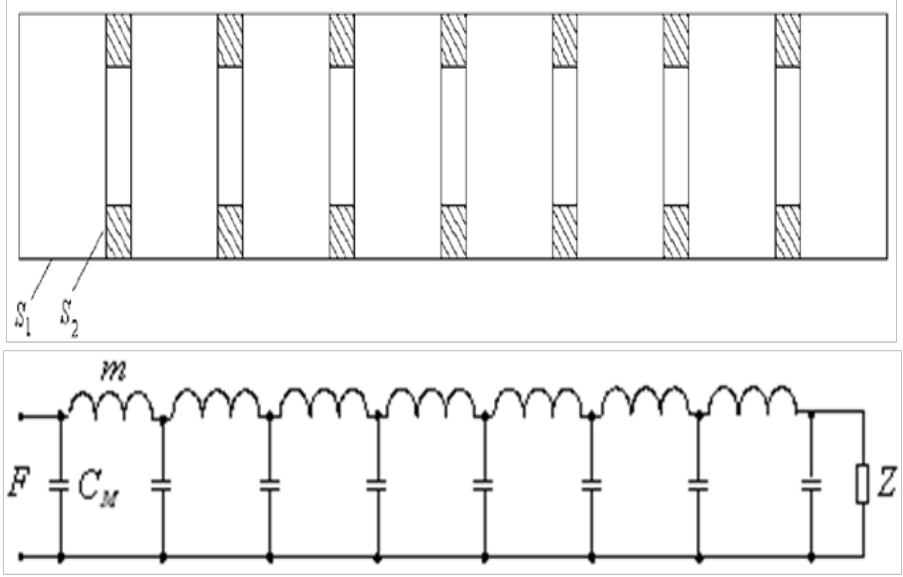

Figure 2 Insect heart multi-chamber acoustic system model.

While simulation, the dimensions of the heart, presented, ${ }^{3}$ were taken into account. The approximate length of the abdomen is about $8 \mathrm{~mm}$. Heart passes through the abdomen in the long tube shape, one end of which is usually closed. Let us suppose the length of the entire cardiac system $L$, equal to $8 \mathrm{~mm}$. The abdominal region has 9-10 segments. The heart is swollen in each segment and divided into chambers. For the most part, the cameras are only in the abdomen, but in the first abdominal segment there is often no isolated camera. Thus, provided that the abdominal section of the Colorado potato beetle has 9 segments, the number of chambers in it equal 8 and they are filled with blood. The length of the spine is $1 \mathrm{o}=10^{-4}[\mathrm{~m}]$, the length of one of the heart system chambers is $1_{\mathrm{k}}=10^{-3}[\mathrm{~m}]$.

\section{Results of the resonant frequency multi-chamber acoustic system calculation}

For resonant frequency determining of the Colorado potato beetle heart, it is necessary to calculate its heart mass $\mathrm{m}$ and its rigidity $\mathrm{C}$ as a multi-chamber resonance system.

Spine cross-sectional area calculation denoted $\mathrm{S}_{2}$. Adopt:

$\mathrm{S}_{2}=\mathrm{S}_{1} / 3$,

Where $\mathrm{S}_{1}$ - chambers cross-sectional area; $\mathrm{d}_{1}$-chamber diameter.

Provided that beetle body diameter is $\approx 3.5 \mathrm{~mm}$, and the stem diameter is $1 / 7$ of total insect body diameter, we obtain insect body diameter $\mathrm{d} 1$, which is $d_{1}=5 * 10^{-4}[\mathrm{~m}]$.

Calculation the cross-sectional area of the camera $\mathrm{S}_{1}$.

$$
S_{I}=\frac{\partial * d_{1}^{2}}{4}\left[\mathrm{~m}^{2}\right]
$$

Then the cross-sectional area of ostia $\mathrm{S}_{2}$ will be $6.53 \times 10^{-8}\left[\mathrm{~m}^{2}\right]$.

Blood density is taken $\rho=10^{3}\left[\mathrm{~kg} / \mathrm{m}^{3}\right]$.

Calculate the mass $\mathrm{m} 0$ of one spine $[\mathrm{kg}]$. The value of $\mathrm{m} 0$ is numerically equal to $6.53 * 10^{-9}[\mathrm{~kg}]$.

The mass of one camera $\mathrm{mk}$ is determined from the expression

$$
\tilde{n}_{k}^{*} \vDash * S_{k} \quad l
$$

The calculated mass magnitude $\mathrm{mk}$ is numerically equal to $19.625^{*}$ $10^{-8}[\mathrm{~kg}]$.

The total mass of the seven osti and eight chambers will be

$$
m_{o k}=8 * m_{\mathrm{k}}+7 * \mathrm{~m}_{\mathrm{o}}
$$

$\mathrm{m}_{\mathrm{ok}}$ is equal to $161.58 * 10^{-8}[\mathrm{~kg}]$.

Total mass of the insect entire heart $\mathrm{m}_{\Sigma}$ equals three total masses of the awns and chambers,

$$
\mathrm{m}_{\Sigma}=3 * \mathrm{~m}_{\mathrm{ok}}=484,74+10^{-8}[\mathrm{~kg}] .
$$

The fluid flexibility in the cavity of one of the chambers $\mathrm{K}_{\mathrm{m}}$, if the heart chamber is modeled by a Helmholtz resonator (see [2]), determines from the expression

$$
K_{M}=\frac{V}{\tilde{a}^{*} p_{a c} * S_{2}^{2}},
$$

Where $V$ - is the volume of the chamber; $\gamma$ - is the specific weight of blood; $p_{a c}$ - acoustic pressure of blood in the system.

We assume that the acoustic pressure inside of the blood chamber is $p_{a c}=20\left[\mathrm{~N} / \mathrm{m}^{2}\right]$, and the specific weight is $\gamma=9810\left[\mathrm{~N} / \mathrm{m}^{3}\right]$. The calculated value of flexibility was $\mathrm{K}_{\mathrm{m}}=0.2337[\mathrm{~m} / \mathrm{N}]$.

The rigidity of the camera is equal to $\mathrm{Ck}=1 / \mathrm{Km}=4.279[\mathrm{~N} / \mathrm{m}]$.

Total rigidity of eight chambers and seven ostia system was defined as

Consequently

$$
\frac{1}{\mathrm{C}_{\Sigma}}=\frac{8}{\mathrm{C}_{\mathrm{k}}}
$$

$$
\mathrm{C}_{\Sigma}=\frac{\mathrm{C}_{\mathrm{k}}}{8}=0,5349[\mathrm{~N} / \mathrm{m}] .
$$

As a calculated result, it was obtained that the resonant frequency of Colorado potato beetle heart is equal to

$$
f_{p e 3}=\frac{1}{\partial} \sqrt{\frac{C_{\dot{O}}}{n_{\dot{o}}}}=1179[\mathrm{~Hz}] .
$$

\section{The discussion of the results}

The impact of vibrations on the heart of the Colorado potato beetle with a given frequency will lead to its rupture. This would entail the death of the Colorado potato beetle. The effects of the disastrous effect of vibrations on living organisms are described in Sokol. ${ }^{1}$ The resonance frequency and stiffness of insets harmful for plants (Colorado beetle) are defined. In the laboratory conditions death of the beetle under the influence of acoustics waves was stated. Experimental studies in which the value of the destructive frequency for the Colorado potato beetle is obtained on a vibrating stand is described in Sapozhkov. ${ }^{2}$ It was obtained that biological death was registered for a beetle with a mass of $100 \mathrm{mg}$ after exposure to him at a frequency of $1500 \mathrm{~Hz}, 4$ hours after exposure to vibrations. 


\section{Conclusion}

a. A method was developed for mechanical system resonant frequencies determining, which thereby make a scheme for a complex multi-chamber system of insect heart based on the electro-acoustic analogies method.

b. Resonant frequency of the multi-chamber acoustic system of the Colorado potato beetles was calculated. Estimated that it is 1179 [Hz].

\section{Acknowledgments}

None.

\section{Conflicts of interest}

Author declares that there are no conflicts of interest.

\section{References}

1. Sokol GI. Features of infrasonic processes in the infrasonic frequency range. Dnepropetrovsk: Promin; 2000. 136 p.

2. Sapozhkov MA. Electroacoustics. Moscow: Communication; 1978. 272

3. A unique experiment conducted on the ISS. Russia. 2014.

4. NASA has sent ants into space. National Geographic. 2014.

5. Sokol GI. OM Duplischeva. Vibration technologies in rigidity and resonant frequency determination of insect bodies. Technologies and Technologies. 2007;1(46):20-24.

6. SN Romanov. Biological effect of vibration and sound. L Nauka. 1991; $210 \mathrm{p}$

7. Encyclopedic dictionary Brockhaus and Efron. 